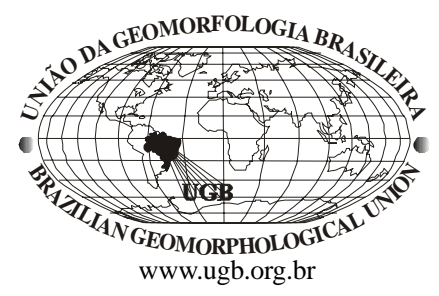

\title{
RELAÇÃO SOLO-RELEVO EM VERTENTES ASSIMÉTRICAS NO PARQUE NACIONAL DA SERRA DOS ÓRGÃOS, RJ
}

\author{
Éder de Souza Martins \\ EMBRAPA Cerrados \\ eder@cpac.embrapa.br
}

Osmar Abílio de Carvalho Júnior
Departamento de Geografia da Universidade de Brasília (UnB)
osmarjr@unb.br

Vinícius Vasconcelos de Souza

Departamento de Geografia da Universidade de Brasília (UnB) vinicius.vascoza@gmail.com

Antônio Felipe Couto Júnior

Departamento de Geografia da Universidade de Brasília (UnB) antoniofelipejr@gmail.com

Sandro Nunes de Oliveira

Departamento de Geografia da Universidade de Brasília (UnB)

sandronunes@unb.br

Roberto Arnaldo Trancoso Gomes

Departamento de Geografia da Universidade de Brasília (UnB) robertogomes@unb.br

Adriana Reatto

EMBRAPA Cerrados

reatto@cpac.embrapa.br

\begin{abstract}
Resumo
O estudo foi realizado no Parque Nacional da Serra dos Órgãos (PARNASO), estado do Rio de Janeiro, no contexto da Serra do Mar e com vegetação típica da Mata Atlântica. O objetivo foi relacionar a organização do solo na paisagem, integrando os fatores pedológicos, geomorfológicos e geológicos. Os solos mostram seqüências assimétricas entre a vertente continental, mais suave, em relação à oceânica, com ruptura brusca de relevo. Os solos mostram polaridade evolutiva crescente entre o topo e base das vertentes. A vertente continental apresenta a seguinte toposseqüência com continuidade pedológica evolutiva: afloramentos rochosos, Neossolos Litólicos, Cambissolos, Argissolos e Latossolos. Por outro lado, a vertente oceânica mostra uma toposseqüência truncada, também com polaridade evolutiva do topo para a base: Afloramentos Rochosos, Cambissolos, Argissolos e Latossolos. A assimetria das vertentes é marcada pela escarpa oceânica formada por uma importante zona de falha na direção NE-SW. Nos compartimentos de Planalto os Neossolos Litólicos são associados localmente a Gleissolos, afloramentos
\end{abstract}


rochosos e Plintossolos Pétricos, desenvolvidos sobre granitos equigranulares e isotrópicos. No compartimento de Planalto Dissecado os Cambissolos são associados localmente a Plintossolos e Neossolos Litólicos e ocorrem sobre relevos multiconvexos relacionados com saprolitos de rochas gnáissicas ou de estrutura de fluxo ígneo. Os Argissolos são associados localmente a Latossolos e Chernossolos em depósitos formados em porções deprimidas de vales encaixados e formados por facetas trapezoidais. Estes ambientes refletem o contínuo processo de erosão por escorregamentos, movimentos de massa e quedas de blocos das porções mais elevadas e a intemperização destes materiais nas porções mais baixas.

Palavras-Chave: Mata Atlântica; Serra do Mar; relevo montanhoso; lineamentos estruturais; sistemas de transformação; pedogênese.

\begin{abstract}
The research was developed in the National Park of Serra dos Órgãos (PARNASO), part of the Serra do Mar complex inside the Atlantic Rainforest located in Rio de Janeiro. The aim was to connect the soil organization in the landscape, integrating pedologic, geomorphologic and geologic factors. It is noted asymmetric soil sequences between smoother continental compared to relief rupture oceanic hillsides. Besides that, the soils show a crescent evolutive polarity between the top and bottom hillside. The continental hillside presents the follow toposequence with continuous pedologic evolution: rock outcrops, Litholic Neosols, Cambisols, Argisols, and Latosols. Otherwise, the oceanic hillside presents truncated toposequence with the same evolutive polarity: rock outcrops, Cambisols, Argisols and Latosols. The hillside asymmetry is pointed by oceanic escarpment made by an important NE-SW fault direction. The Plateau unit is characterized by Litholic Neosols locally associated to Gleysols, rock outcrops and Petric Plinthosols developed on equigranular and isotropic granites. The Dissected Plateau unit is pointed by Cambisols locally associated to Plinthosol and Litholic Neosol on multiconvex relief related to gneiss and igneous flux structure rock saprolites. The Valleys unit is distinguished by Argisols associated to Latosols and Chernosols in valley deposits depressions related to trapezoidal facets. These features reflect the process of erosion by landslides, debris flows and rock falls for higher portions, and subsequent sediment pedogenesis in lower landscapes.
\end{abstract}

Keywords: Atlantic rainforest; Serra do Mar; mountain relief; structural lineaments; transformation systems; pedogenesis.

\section{Introdução}

A pedosfera é entendida como a interface entre litosfera, hidrosfera, biosfera e atmosfera na superfície terrestre, que é responsável pela formação da cobertura pedológica e da superfície geomórfica como resultado das interações dessas esferas ao longo do tempo (Juma, 1999). Queiroz-Neto (2002) afirma que o estudo dessas relações e do processo de análise da formação de solos na paisagem começa com o conceito de catena de Milne (1934). Catena, para este autor, é uma unidade prática de mapeamento que agrupa solos relacionados por condições topográficas e representam a distribuição dos solos na paisagem.

A idéia de tridimensionalidade da organização do solo, ou catena, indica que os perfis de solos sucedem-se nas vertentes e apresentam uma relação genética em diferentes formas de relevo (Sommer \& Schlichting, 1997; Bockheim et al., 2005). Este conceito de catena é uma base fundamental para o desenvolvimento de ferramentas metodológicas que relacionam atributos da paisagem com o solo. Desta forma, o solo é a materialização dos processos morfogenéticos que ocorrem na paisagem, caracterizando a interdependência solorelevo (Bockheim et al., 2005).

A partir deste conceito foram desenvolvidas várias abordagens metodológicas, levando sempre em consideração as polaridades das vertentes como unidades de observação. As principais contribuições podem ser creditadas aos arranjos formalizados pela escola pedológica francesa, que operacionalizaram a noção de diferenciação lateral da cobertura pedológica a partir de sua análise estrutural detalhada e do princípio básico dos Sistemas de Transformação Pedológica (Delvigne, 1965; Bocquier, 1971; Chauvel, 1976; Boulet, 1978). Esses trabalhos permitiram posicionar o solo nas vertentes em relação à história climática e geomorfológica, além de compreender o movimento da água na paisagem (Gobin et al, 2001). Apesar de muito eficiente, a maior desvantagem desta abordagem é o elevado custo de tempo, recursos e necessidade de equipes preparadas para estes levantamentos (Lagacherie, 1995). Recentemente, o advento dos Sistemas de Informação Geográfica (SIG) permitiu a modelagem 
matemática do relevo e a integração de dados discretos e contínuos distribuídos na paisagem integrando os fatores ambientais por meio de técnicas geoestatísticas, também designado como Mapeamento Digital de Solos (Lagacherie et al., 2006). Esta abordagem não prescinde de estudos de campo, mas contribui na escolha de áreas representativas para estudos detalhados e posteriormente na extrapolação dos dados por meio de modelagem (Sommer \& Schlichting, 1997).

Outro conceito importante sobre a relação solopaisagem é o balanço entre os processos químicos e físicos nas vertentes. A idéia principal é que existem mecanismos sistêmicos que promovem um equilíbrio dinâmico na paisagem, como o conceito de bio-resistasia de Erhardt (1956). Estes conceitos de equilíbrio relacionam o desenvolvimento das superfícies geomórficas com a maturidade dos solos. Superfícies geomórficas mais antigas tendem a ser mais estáveis, mais homogêneas e com coberturas pedológicas mais maduras e menos complexas (Vidal-Torrado \& Lepsch, 1999; Teramoto et al., 2001).

Outra conseqüência do conceito de equilíbrio das vertentes está relacionada com os processos de erosão e deposição na paisagem, formando superfícies geomórficas erosionais e deposicionais, geralmente contíguas espacialmente (Daniels et al., 1971). Por outro lado, as superfícies mais antigas são mais estáveis e normalmente relacionadas com os divisores de bacias e ambientes erosionais, enquanto que as superfícies mais jovens ocorrem em áreas de acumulação e ambientes deposicionais (Graham et al., 1990).

Para explicar melhor essa relação entre solo e relevo, Sommer e Schlichting (1997) desenvolveram o conceito de catenas arquetípicas, dependentes dos processos de (im)mobilização e os regimes hidrológicos, quais sejam: (i) catenas de transformação (transformation catenas), onde não são evidenciados ganhos ou perdas de elementos ou componentes do solo, mas somente processos de transformação, (ii) catenas de lixiviação (leaching catenas), com perdas de componentes e sem evidências de ganhos, e (iii) catenas de acumulação (accumulation catenas), mostrando ganhos e sem perdas de materiais em nenhuma porção. As catenas de translocação (translocation catenas) são subtipos das de lixiviação ou de acumulação, onde as transferências e acumulações estão em equilíbrio. As catenas relacionadas com superfícies geomórficas de diferentes idades, as catenas temporais (chrono catenas), são consideraras como um subgrupo de todas as outras.

Nesse sentido, o objetivo deste trabalho é mostrar a relação do solo com as formas de relevo no Parque Nacional da Serra dos Órgãos, PARNASO, considerando o papel da dinâmica e organização da cobertura pedológica nas vertentes.

\section{2. Área de estudo}

\subsection{Localização e Clima}

O Parque Nacional da Serra dos Órgãos (PARNASO) localiza-se no estado do Rio de Janeiro e está representado por uma área protegida de 10.653 ha, abrangendo os municípios de Teresópolis, Petrópolis, Magé e Guapimirim a 16 km ao norte da Baía de Guanabara (Figura 1). O município com maior área inserida na Unidade de Conservação é Petrópolis com 42,9\%, seguido de Guapimirim (17,7\%) e Magé $(13,4 \%)$. A área compõe parte das seguintes cartas topográficas do IBGE em escala 1:50.000: Itaipava (SF-23-ZB-I-4), Teresópolis (SF-23-Z-B-II-3), Petrópolis (SF-23-Z-BIV-2) e Itaboraí (SF-23-Z-B-V-1).

Segundo a classificação de Köppen, o clima da região é mesotérmico brando superúmido com temperatura média variando entre $13^{\circ} \mathrm{e} 23^{\circ} \mathrm{C}$ e índice pluviométrico médio anual entre $2.300 \mathrm{~mm}$ e $3.000 \mathrm{~mm}$, caracterizando verões brandos sem estação seca com abundância das precipitações nos meses de inverno (Nimer, 1977; INMET, 2007; ICMBio, 2007). Nos períodos mais frios é freqüente a ocorrência de névoas e chuvas determinadas pelas frentes frias que vêm do sul. Além disso, o relevo faz o controle do regime das chuvas correlacionadas com a dinâmica da Massa Tropical Atlântica e da Massa Polar Atlântica vigente na região. Este controle orográfico promove uma maior intensidade pluviométrica nas vertentes oceânicas em relação às vertentes continentais (Davis \& Naghettini, 2000; ICMBio, 2007).

A Serra do Mar com seu mosaico de Mata Atlântica é considerada como hotspot para conservação da biodiversidade (Myers et al., 2000).

\subsection{Contexto Geológico}

O Complexo da Serra do Mar estende-se por $1.000 \mathrm{~km}$ do Rio de Janeiro ao norte de Santa Catarina como uma serra marginal de borda de planalto, com desnível acentuadamente maior para o oceano, mas possuindo taludes e vertentes abruptas nos dois flancos (Cordani \& Girardi, 1967). Este sistema é constituído por um conjunto de blocos altos e baixos conjugados em maciços diversos, formados por rochas metamórficas pré-cambrianas e intrusões de granitos e diques de diabásio (Tupinambá, 1999).

O PARNASO faz parte do Complexo Paraíba do Sul, que é constituído por gnaisses, granitos pós-tectônicos da Suíte Intrusiva da Serra dos Órgãos e por sedimentos aluvionares e litorâneos (Brasil, 1983, Silva et al., 2000). As litologias pré-cambrianas e eopaleozóicas estão individualizadas em seis entidades de mapeamento (Penha et al. 1979; Pinto et al., 1980): Complexo Rio Negro, Leucogranito Gnaisse, Batólito Serra dos Órgãos, Granito Andorinha, 

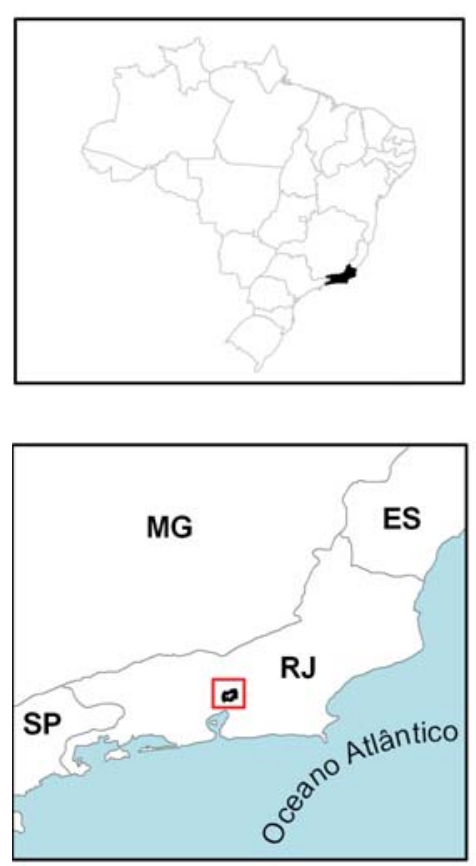

Projeção - UTM

Datum - SAD69

Fuso - 23S

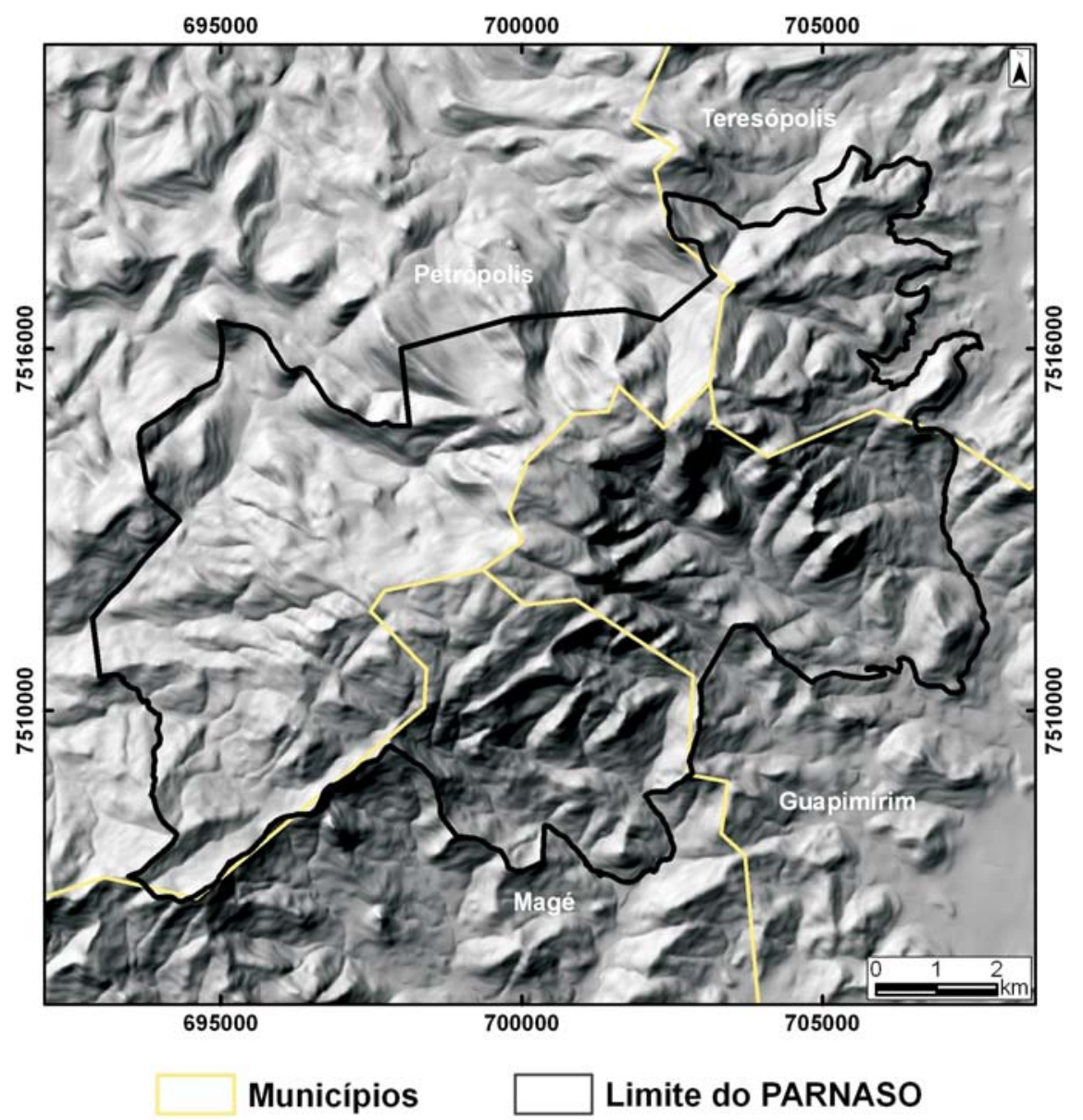

Figura 1 - Mapa de Localização do Parque Nacional da Serra dos Órgãos (PARNASO).

Granito Nova Friburgo e Corpos intrusivos mesozóicocenozóicos. Os depósitos aluvionares também foram reconhecidos, principalmente tangenciando o limite sudeste do PARNASO (Ferrari et al., 1981).

\subsection{Neotectônica}

A região pertence ao contexto do Rifte Continental do Sudeste do Brasil (RCSB), que seria resultado da evolução histórica da diferença entre as tensões nas bordas leste e oeste da placa Sul-Americana durante o Cenozóico (Riccomini, 1989). Mecanismos de extensão e compressão de direção EW seriam alternados durante o Cenozóico, confirmados por dados sismológicos atuais, com esforços compressivos, também atribuídos à interação da placa de Nazca em subducção sob a placa Sul-Americana, esta em deriva para oeste (Assumpção, 1992).

O RCSB é formado por um conjunto de blocos escalonados em direção a leste (Figura 2), que formam na parte continental a Serra da Mantiqueira e a Serra do Mar como altos estruturais, intercalados pelos grábens do Paraíba e da Guanabara como baixos estruturais no contexto da região estudada (Asmus \& Ferrari, 1978; Ferrari, 2001; Riccomini, 1989).

O registro sedimentar e ígneo dos grábens são as principais evidências de evolução do regime tectônico do RCSB (Riccomini, 1989; Ferrari, 2001). Os altos estruturais, como é o caso da área do PARNASO, com forte tendência à erosão, geralmente não apresentam registros da evolução da tectônica. Entretanto, Hartwig (2006) apresentou estudo morfotectônico do PARNASO, indicando seis regimes tectônicos superpostos em consonância aos estudos geológicos e de evolução dos grábens regionais, a seguir:

(1) Transcorrente sinistral, durante o Pré-Cambriano e Cambriano, com binário de direção geral EW e resultante de compressão de direção NE-SW e distensão NW-SE; 


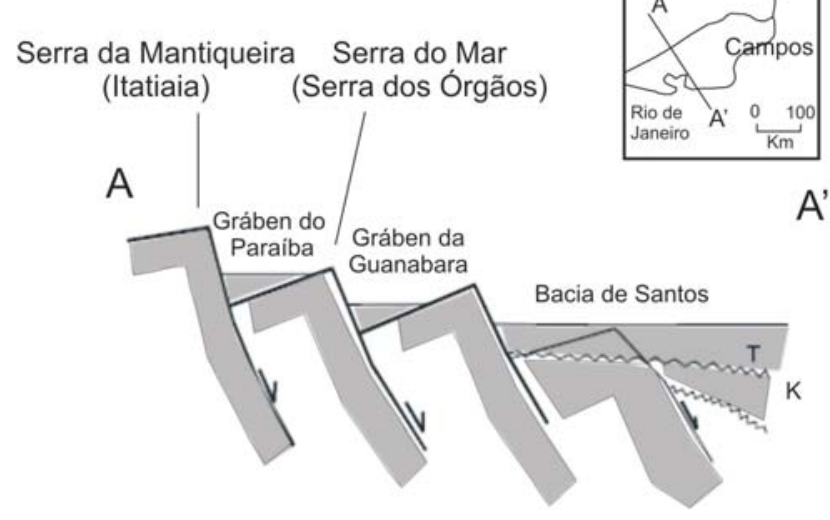

Figura 2- Perfil esquemático dos falhamentos escalonados e basculamento de blocos resultantes do tectonismo cenozóico relacionado ao Rifte Continental do Sudeste do Brasil (Riccomini, 1989; Asmus \& Ferrari, 1978).

(2) Transcorrente sinistral, ativo no Eocretáceo, semelhante ao primeiro;

(3) Transcorrente sinistral, ativo entre o Eocretáceo e Neocretáceo-Paleoceno, responsáveis, respectivamente, pela colocação do enxame de diques básicos que ocorre na porção centro ocidental do estado do RJ, e por diques de rochas alcalinas e centros intrusivos dispostos ao longo do Alinhamento Magmático de Cabo Frio. Estes regimes ocasionaram intenso fraturamento de orientação NE-SW, distribuído por todo o PARNASO;

(4) Distensão NW-SE, ativo no Eoceno, considerado como gerador do RCSB. Embora as feições rúpteis associadas a esta fase tectônica não estejam muito evidentes, sua principal consequêencia no PARNASO seria a compartimentação do relevo da sua porção sul-sudeste em blocos alongados e escalonados abatidos para sudeste. Concomitante a este abatimento, deu-se a deformação de uma antiga superfície de aplainamento (Japi), que teria nivelado a cimeira da Serra dos Órgãos em torno de 2.000 m;

(5) Transcorrente dextral, durante o Pleistoceno e Holoceno, com binário de direção E-W e resultante de compressão de direção NW-SE e distensão NE$\mathrm{SW}$. Este sistema reativou fraturas de orientação NESW, hoje realçadas pelas facetas trapezoidais observadas ao longo do vale do Rio do Bonfim; e

(6) Compressão de direção E-W, atual.

\subsection{Contexto Geomorfológico}

O PARNASO pertence à Unidade Morfoescultural Cinturão Orogênico do Atlântico (Dantas et al., 2001), dividido nos Domínios Morfoestrutural do Planalto Atlântico e das Depressões Tectônicas Mesozóico-Cenozóicas. Esses domínios subdividem-se nas Regiões do Planalto e Escarpas da Serra dos Órgãos e na Região do Rifte da Guanabara (Silva, 2003). Possui relevo montanhoso, apresentando suas maiores elevações na faixa que acompanha a linha divisória dos municípios que corresponde ao divisor de bacias. De modo geral, quase não se observa superfícies planas e quase 50\% da área do Parque são compostas de encostas com mais de $30^{\circ}$ de declividade (ICMBio, 2007).

As unidades morfoestruturais Planalto e Escarpas da Serra dos Órgãos se distribuem continuamente de Itaguaí, a sul do Estado, até o município de Campos de Goitacazes, a norte. É um segmento de grande representatividade areal e de altitudes elevadas, chegando a atingir $2263 \mathrm{~m}$. Em alguns pontos o contato com a Depressão Interplanáltica da Baía de Guanabara é brusco e retilíneo. Possui controle estrutural do embasamento pré-cambriano, onde a dissecação atual da paisagem segue a orientação preferencial NNE-SSW, representada pela disposição das unidades de Morros e Degraus reafeiçoados, tanto na borda interiorana quanto para a borda voltada para o litoral e pela unidade de terraços e planícies fluviais (Silva, 2003).

Estes planaltos são interpretados por diversos autores como pertencente ao ciclo de aplainamento Sul-Americano (King, 1956) ou Japi (Almeida, 1964), desenvolvida durante o Cretáceo Superior e o Paleoceno. Para este último autor, quando não deformada tectonicamente a superfície Japi nivela as cristas das serras residuais do Planalto Atlântico, entre 1000 e 1300 m de altitude, mas no caso da Serra dos Órgãos o planalto ocorre nivelado em torno de $2000 \mathrm{~m}$. Estudos mais recentes confirmam a existência da superfície de aplainamento Japi nestas regiões, deformadas pela atividade neotectônica desenvolvida durante o Terciário (Zalán, 2004; Hartwig, 2006). Ferrari (2001) indica que este aplainamento restringiu-se ao Neocretáceo, devido às rochas alcalinas efusivas de idade de $65 \mathrm{Ma}$, preservadas nos sedimentos da bacia do Macacu.

\subsection{Uso e Cobertura do Solo}

O uso e cobertura do solo são representados por áreas urbanas, agrícolas, pastagens e áreas de proteção ambiental (Parque Nacional da Serra dos Órgãos e Área de Proteção Ambiental de Petrópolis). De acordo com Rizzini (1979) são classificadas quatro fitofisionomias da Mata Atlântica: Floresta Pluvial Baixo-Montana, Floresta Pluvial Montana, Floresta Pluvial Alto-Montana e Campos de Altitude.

A Floresta Pluvial Baixo-Montana ocorre nos fundos de vales onde predominam solos bem drenados como os 
Argissolos e alguns Latossolos. A sua localização varia entre 500 e $800 \mathrm{~m}$ de altitude. Esta fisionomia vegetal apresenta normalmente apenas o estrato arbóreo, com o interior da mata composto por uma densa vegetação, mas sem estratos definidos (Alonso, 1977; Martinelli, 1989).

A Floresta Pluvial Montana ocorre em altitudes que variam entre 600 e $1600 \mathrm{~m}$. Também estão associados a Argissolos e Latossolos. No complexo arbóreo pode apresentar espécies que atingem $40 \mathrm{~m}$ de altura. Também pode ser encontrado muitas palmeiras e samambaias, não muito comuns na Floresta Baixo-Montana.

As árvores possuem troncos tortuosos cobertos por camada de musgos e epífitas na Floresta Pluvial AltoMontana. Ademais, também é encontrada significativa diversidade de espécies arbustivas. Essa floresta é uma típica mata úmida, localizada entre as altitudes de 1300 e 1800 m e em solos rasos, especialmente Cambissolos. Freqüentemente é envolta por densas nuvens durante longos períodos (Alonso, 1977; Martinelli, 1989).

Os Campos de Altitude localizam-se acima dos $1800 \mathrm{~m}$, com baixas declividades e entremeadas com afloramentos rochosos e solos hidromórficos, sendo constituída por uma vegetação baixa herbáceo-arbustiva e mais aberta.

\section{Metodologia}

\subsection{Trabalhos de campo e laboratório}

Para obter as classes de solos e as suas unidades de mapeamentos do PARNASO foram feitas duas campanhas de campo para reconhecimento e análise das diferentes unidades de paisagem (Martins et al., 2004) observadas durante o estudo da travessia Petrópolis-Teresópolis (Figura 3). A escolha pela travessia se explica pela dificuldade em acessar os diferentes compartimentos geomorfológicos constituído por um relevo montanhoso e escarpado. Durante a travessia foi possível obter informações sobre as unidades de paisagem, ou seja, as correlações espacias entre solo, relevo e vegetação. Além disso, foram coletadas 80 amostras de solos por trado em 40 pontos do Parque (Figura 3). A localização da coleta dessas amostras abarcaram todos os compartimentos da vertente continental possibilitando a acurácia no estudo proposto nesse trabalho. Tais amostras foram submetidas às análises físicas e químicas para obter as classes de solos.

Nas análises foram determinados $\mathrm{pH}$ em água, $\mathrm{pH}$ em $\mathrm{KCl}$, alumínio $(\mathrm{Al})$, fósforo $(\mathrm{P})$, potássio $(\mathrm{K})$, cálcio $(\mathrm{Ca})$, magnésio (Mg), hidrogênio+alumínio (H+Al) e matéria orgânica, além da composição granulométrica, seguindo os procedimentos do Manual de Métodos de Análise de Solo (Embrapa, 1997).

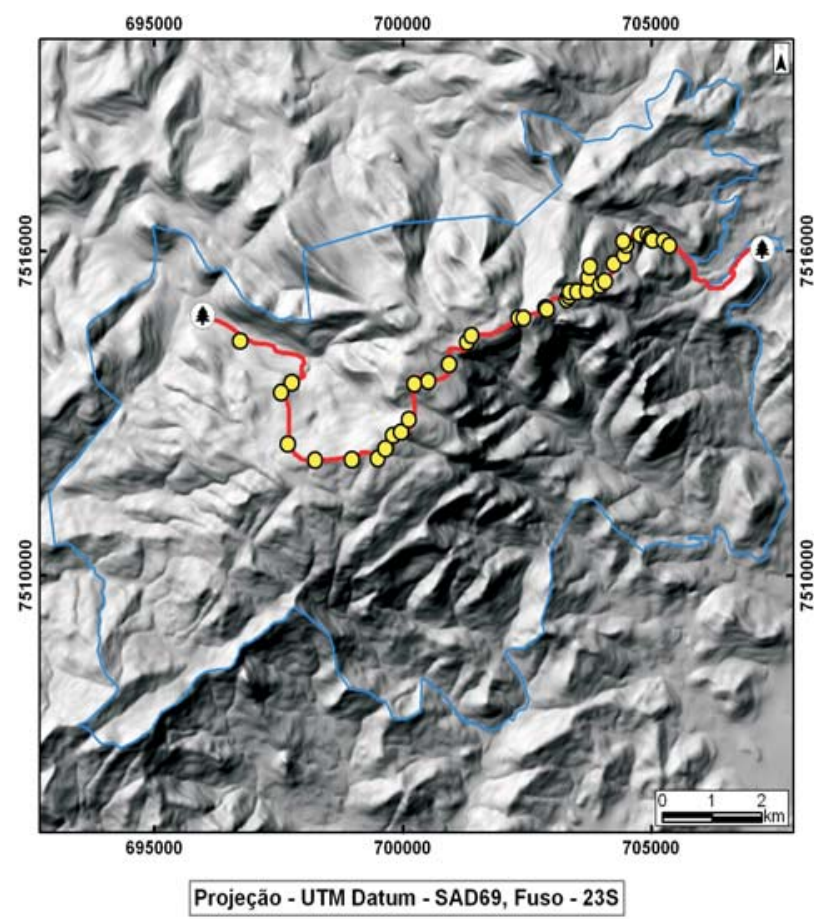

Limite do PARNASO Trilha da Travessia

- Sede Petrópolis (a esqueda)/Teresópolis (a direita)

OPontos de Coleta

Figura 3 - Mapa dos Pontos Coletados.

\subsection{Critérios para Classificação dos Solos e Unidades de Mapeamento}

A classificação dos solos foi realizada a partir dos resultados das análises químicas e físicas das amostras coletadas por trado, sem considerar a descrição de perfis de solo. Os critérios considerados na classificação foram: saturação por base, saturação de alumínio, CTC, atividade da fração argila, delta pH, e textura. Além disso, também foram correlacionados a essas análises os domínios geomorfológicos e fitofisionômicos da área do Parque (Oliveira et al., 2007).

Eventualmente, as manchas de solo de pequena expressão areal foram agrupadas em unidades de mapeamento na forma de associações (Embrapa, 1992). A confecção do mapa esquemático de solos empregou os seguintes materiais: (a) o Modelo Digital de Terreno (MDT) a partir de base cartográfica na escala 1:50.000, em formato digital, contendo curvas de nível com eqüidistância de 20 m, pontos cotados e hidrografia adquiridas do Instituto Brasileiro de Geografia e Estatística - IBGE; (b) um mosaico de fotografias digitais ortorretificadas em preto e branco na escala 1:10.000. 
O MDT agregou informações sobre o relevo e seus parâmetros derivados, tais como declividade, altitude e curvatura. Na correção das curvas de nível foram conferidos a conectividade, a falta de segmentos de linhas e os valores das cotas. Para as drenagens conferiu-se o lineamento da drenagem em relação às curvas de nível, a conectividade, o tamanho mínimo de segmento de linha e a direção de fluxo.

A interpolação foi realizada pelo método TOPOGRID com uma resolução espacial de $10 \mathrm{~m}$, que emprega o algoritmo desenvolvido por Hutchinson (1989), com o propósito de aplicação em estudos hidrológicos. Além do procedimento de interpolação foram utilizadas as técnicas para a obtenção de um MDT hidrologicamente corrigido considerando os seguintes aspectos (Martz \& Garbrecht, 1995; Turcotte et al. 2001): (a) eliminação das depressões artificiais (Jenson \& Domingue, 1987), (b) introdução de informações sobre as localizações de rede de drenagem em regiões planas (Tarboton, 2005), e (c) limitações inerentes dos métodos para a obtenção da direção de fluxo (O’Callaghan \& Mark, 1984, Tarboton, 1997).

\subsection{Confecção dos Diagramas de Roseta}

O diagrama de roseta classifica as variações na orientação dos lineamentos estruturais. No presente trabalho esse diagrama foi obtido para cada ordem de drenagem com finalidade de demonstrar a assimetria entre a vertente oceânica e continental e a sua relação com a formação do solo.

Os segmentos de linhas referentes às ordens de drenagem, conforme Strahler (1952), foram obtidos pelo algoritmo
Terrain Analysis Using Digital Elevation Model (TauDEM). Após esse procedimento, foi utilizado o diagrama de roseta para cada ordem da drenagem das Escarpas Serranas e dos Planaltos Serranos.

\section{Resultados e Discussão}

As classes de solos observadas no PARNASO e a sua relação com os fatores geoambientais são apresentadas na Tabela 1 e 2.

Nota-se que os fatores geológicos e geomorfológicos estão intimamente associados à organização pedológica na paisagem, conforme foi observado por outros autores em estudos regionais (Rossi \& Pfeifer, 1991; Rossi \& Queiroz Neto, 2001).

\subsection{Unidades de Mapeamento}

A integração dos dados de solos com a interpretação do MDT e das fotografias aéreas permitiu a confecção de um mapa esquemático de solos do PARNASO (Figura 4). A delimitação das unidades de mapeamento foi obtida pela correlação existente entre os fatores geoambientais estudados.

Desta forma, tornam-se evidentes a relação dos Campos de Altitude, facilmente detectados por fotografia aérea, com a exposição dos afloramentos rochosos e os Neossolos Litólicos. Por outro lado, as porções deprimidas em vales são distinguidas no MDT e relacionam-se com os Latossolos e Argissolos, com vegetação arbórea.

Tabela 1 - Análises Químicas e Físicas dos Solos mais representativos

\begin{tabular}{|c|c|c|c|c|c|c|c|c|c|c|c|c|c|c|c|c|c|}
\hline $\begin{array}{l}\text { Classe } \\
\text { de solo }\end{array}$ & $\begin{array}{l}\text { Prof. } \\
(\mathrm{cm})\end{array}$ & $\begin{array}{l}\text { Areia } \\
\text { Grossa } \\
2-0,2 \\
(\mathrm{~mm})\end{array}$ & $\begin{array}{c}\text { Areia } \\
\text { Fina } \\
0,2-0,05 \\
(\mathrm{~mm})\end{array}$ & $\begin{array}{c}\text { Silte } \\
0,05-0,002 \\
(\mathrm{~mm})\end{array}$ & $\begin{array}{l}\text { Argila } \\
<0,002 \\
(\mathrm{~mm})\end{array}$ & Silte/Argila & $\mathrm{pH} \mathrm{H} \mathrm{H}_{2} \mathrm{O}$ & $\mathrm{pH} \mathrm{KCl}$ & $\mathrm{Al}$ & $\mathrm{Ca}$ & $\mathrm{Mg}$ & $\underset{1}{K}$ & $\mathrm{H}+\mathrm{Al}$ & $T$ & MO & $\underset{g \mathrm{~kg}^{-1}}{V}$ & M \\
\hline \multirow[t]{2}{*}{ Neossolo Litólico distro-úmbrico } & $0-20$ & 42 & 26 & 12 & 20 & 0,60 & 4,22 & 3,92 & 2,88 & 0,08 & 0,09 & 0,101 & 16,30 & 16,57 & 78,7 & 16,5 & 636,00 \\
\hline & $20-40$ & 42 & 27 & 09 & 22 & 0,41 & 4,10 & 3,92 & 2,07 & 0,02 & 0,04 & 0,061 & 12,86 & 12,98 & 35,6 & 9,2 & 692,10 \\
\hline \multirow[t]{2}{*}{ Neossolo Litólico húmico } & $0-23$ & 34 & 39 & 12 & 15 & 0,80 & 4,95 & 3,96 & 3,27 & 0,22 & 0,18 & 0,21 & 23,02 & 16,57 & 123,7 & 25,8 & 636,00 \\
\hline & $23-40$ & 39 & 35 & 10 & 16 & 0,63 & 5,13 & 4.25 & 2,83 & 0,11 & 0,13 & 0,14 & 20,58 & 23,63 & 77,2 & 18,0 & 692,10 \\
\hline \multirow[t]{2}{*}{ Cambissolo Háplico Ta distrófico } & $0-20$ & 43 & 27 & 08 & 22 & 0,36 & 4,09 & 4,14 & 1,39 & 0,09 & 0,08 & 0,05 & 9,00 & 9,22 & 33,4 & 24,1 & 366,20 \\
\hline & $20-40$ & 37 & 26 & 07 & 30 & 0,23 & 4,35 & 4,35 & 0,76 & 0,06 & 0,04 & 0,03 & 6,44 & 6,57 & 20,8 & 19,6 & 279,40 \\
\hline \multirow[t]{2}{*}{ Gleissolo Melânico alitico } & $0-22$ & 10 & 66 & 12 & 12 & 1,00 & 4,28 & 4,32 & 1,39 & 0,09 & 0,08 & 0,16 & 19,34 & 19,83 & 157,6 & 24.7 & 566,20 \\
\hline & $22-40$ & 10 & 68 & 10 & 12 & 0,83 & 4,06 & 4,11 & 3,22 & 0,13 & 0,20 & 0,09 & 18,86 & 19,18 & 145,0 & 16,6 & 650,09 \\
\hline \multirow{2}{*}{$\begin{array}{l}\text { Argissolo Bruno-Acinzentado } \\
\text { alitico }\end{array}$} & $0-22$ & 47 & 27 & 12 & 14 & 0,86 & 4,70 & 4,29 & 4,05 & 0,10 & 0,13 & 0,18 & 19,20 & 19,61 & 133,6 & 21,1 & 657,00 \\
\hline & $22-40$ & 48 & 26 & 06 & 20 & 0,30 & 4,98 & 3,47 & 3,48 & 0,04 & 0,05 & 0,06 & 17,28 & 17,43 & 50,0 & 8,9 & 796,80 \\
\hline \multirow[t]{2}{*}{ Argissolo Amarelo diströfico } & $0-21$ & 57 & 30 & 04 & 09 & 0,44 & 4,40 & 4,05 & 4,05 & 1,39 & 0,03 & 0,11 & 8,72 & 9,42 & 34,4 & 74,1 & 157,90 \\
\hline & $21-40$ & 50 & 31 & 06 & 13 & 0,46 & 4,69 & 4,08 & 3,48 & 2,30 & 0,53 & 0,09 & 9,08 & 10,47 & 29,9 & 132,6 & 147,80 \\
\hline \multirow[t]{2}{*}{ Latossolo Amarelo distrófico } & $0-20$ & 35 & 18 & 15 & 32 & 0,47 & 4,78 & 4,07 & 0,81 & 1,52 & 0,20 & 0,002 & 5,42 & 7,14 & 14,3 & 241,1 & 32,49 \\
\hline & $20-40+$ & 46 & 10 & 13 & 31 & 0,42 & 4,63 & 4,03 & 0,91 & 0,75 & 0,17 & 0,001 & 4,70 & 5,62 & 10,8 & 163,8 & 52,60 \\
\hline
\end{tabular}


Martins, E.S. et al.

Tabela 2 - Classes de Solos e sua relação com os fatores geoambientais.

\begin{tabular}{|c|c|c|}
\hline Classe de Solos & Geomorfologia & Material de Origem \\
\hline Neossolo Litólico distro-úmbrico & $\begin{array}{l}\text { Planaltos Dissecados e } \\
\text { Planalto do Açu }\end{array}$ & $\begin{array}{l}\text { Biotita Granitos, Granodioritos } \\
\text { Gnáissicos }\end{array}$ \\
\hline Neossolo Litólico húmico & $\begin{array}{l}\text { Planaltos Dissecados e } \\
\text { Planalto do Açu }\end{array}$ & $\begin{array}{l}\text { Biotita Granitos, Granodioritos } \\
\text { Gnáissicos e Granito Andorinha }\end{array}$ \\
\hline Gleissolo Me lânico alítico & Planalto do Açu & Granito Andorinha \\
\hline Cambissolo Háplico Ta dis trófico & $\begin{array}{l}\text { Planaltos Dissecados e } \\
\text { Planalto da Pedra do Sino }\end{array}$ & $\begin{array}{l}\text { Biotita Granitos, Granodioritos } \\
\text { Gnáissicos e Granito Andorinha }\end{array}$ \\
\hline $\begin{array}{l}\text { Argissolo Bruno-Acinzentado } \\
\text { alítico }\end{array}$ & Planalto da Pedra do Sino & Granito Andorinha \\
\hline Argissolo Amarelo distrófico & Planalto da Pedra do Sino & Granito Andorinha \\
\hline Latos solo Amare lo distrófico & $\begin{array}{l}\text { Vales do Bonfim e do } \\
\text { Paquequer }\end{array}$ & Sedimentos \\
\hline
\end{tabular}

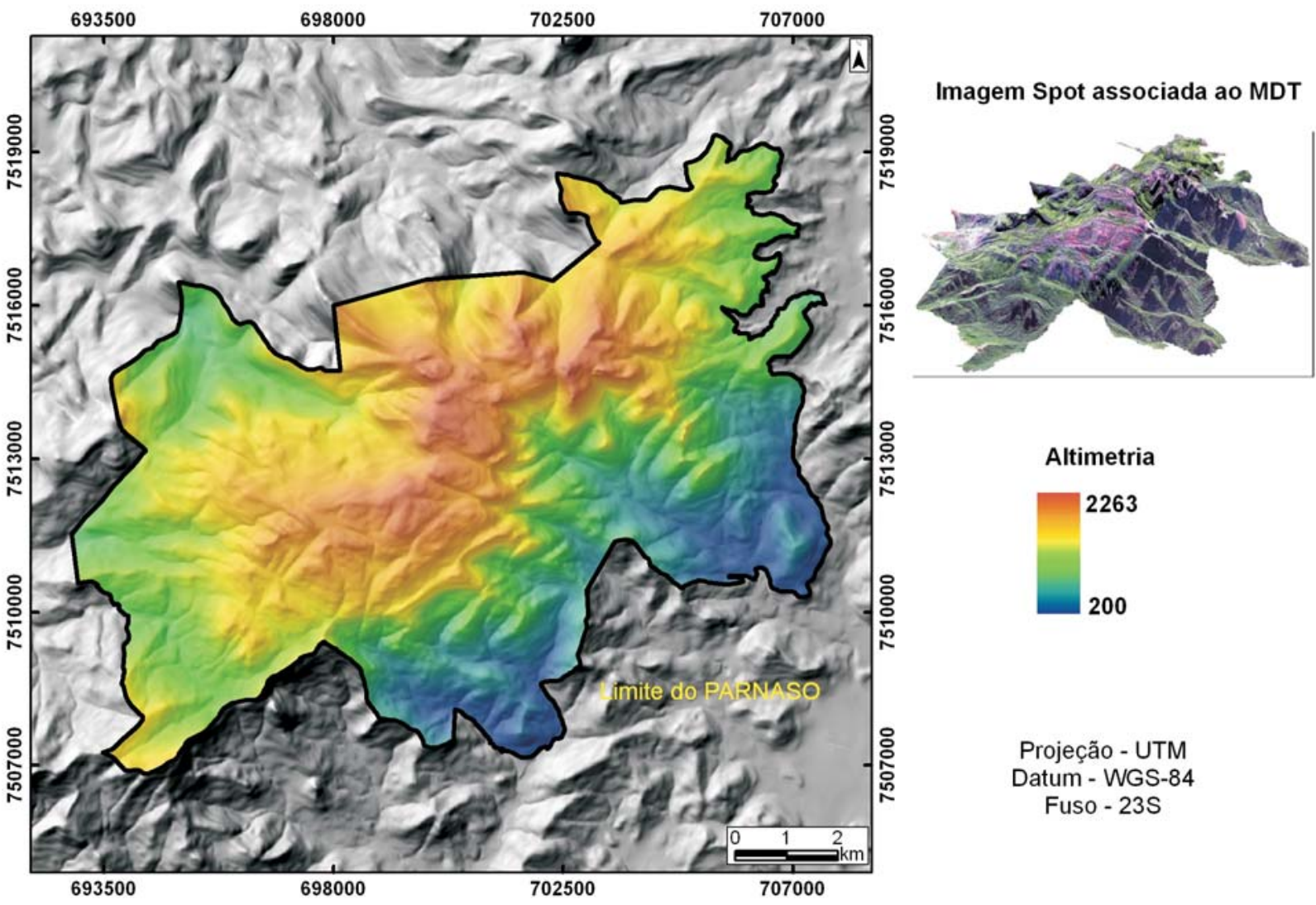

Figura 4 - Modelo Digital do Terreno da Região do PARNASO. 


\subsection{Aspectos Geológicos e Geomorfológicos}

A vertente continental apresenta relevo mais suave que a vertente oceânica, com ruptura brusca. Esta assimetria entre as duas vertentes é controlada pela organização litoestrutural, especialmente a direção e mergulho dominante das foliações das rochas pré-cambrianas e das zonas de falhas e fraturas. As foliações medidas por Tupinambá (1999) mostram uma direção NE-SW, com mergulhos variados para NW, concordante com o caimento geral da vertente continental. Por outro lado, a ruptura de relevo, que separa a vertente continental da oceânica, é definida por uma escarpa de falha formada por uma reativação distensiva de lineamentos do Pré-Cambriano durante o Eoceno, responsável pela formação do RCSB, como descreveu Hartwig (2006).

Desta forma, a vertente continental representa um bloco que foi relativamente alçado, na forma de um Horst, separado da vertente oceânica pela escarpa de falha e que forma um bloco rebaixado relacionado com a formação do Gráben da Guanabara na acepção de Ferrari (2001). Em outras palavras, na área estudada a vertente continental é representada por um alto estrutural, enquanto que a vertente oceânica é um baixo estrutural, separados entre si por uma escarpa de falha.

A vertente continental é dividida em duas unidades geomorfológicas mais importantes, Planaltos e Planaltos Dissecados (Oliveira et al. 2007). O controle destas duas unidades relaciona-se principalmente ao tipo de trama dos granitos e gnaisses. Rochas graníticas equigranulares e isotrópicas geralmente estão controlando o topo dos Planaltos, enquanto que as rochas gnáissicas e graníticas com fluxo ígneo estão relacionadas aos Planaltos Dissecados com formas multiconvexas (Penha et al., 1979; Pinto et al., 1980).

Outro fator estrutural importante é a direção de fraturas NW-SE que controlam os vales mais importantes, tanto na vertente continental, como na oceânica. Estes vales alongados apresentam terraços confinados e separados por facetas trapezoidais de direção NE-SW, como observado no vale do Bonfim (Hartwig, 2006).

Todas as vertentes das unidades geomorfológicas apresentam assimetria relacionada com os fatores estruturais, especialmente a orientação das fraturas. Geralmente, as vertentes que são paralelas às fraturas mais penetrativas apresentam maior declividade e superfície com desenvolvimento incipiente de solo, pois o processo de esfoliação e erosão é mais eficiente que a de formação de solo. Por outro lado, as vertentes opostas desenvolvem solos mais espessos, pois o processo erosivo é mais lento e o intemperismo químico é mais eficiente. Neste caso, eventuais movimentos de massa são de maior magnitude que na vertente oposta (Figuras 5, 6 e 7), conforme foi descrito em áreas semelhantes por De Ploey \& Cruz (1979).

\subsection{Padrões de Direções de Lineamentos Morfoestruturais}

Os padrões de lineamentos morfoestruturais mostram as principais direções que controlam o relevo observado no PARNASO, conforme foi descrito por Hartwig (2006). Entretanto, este autor não separou as direções de drenagens por ordem de rio, como está apresentado na Figura 8.

O par conjugado NE-NW é o mais evidente, que está relacionado com a foliação das rochas pré-cambrianas e as zonas de falhas mais importantes, especialmente a direção NE. Nas drenagens de primeira ordem pode ser observado que este par NE-NW é o mais freqüente. Nas drenagens de segunda ordem da vertente oceânica a direção dominante é NW, enquanto que na vertente continental é a direção EW. Finalmente, as drenagens de terceira ordem mostram direção dominante NW na vertente oceânica, enquanto que na vertente continental as direções NE e EW-NW.

Estas diferenças de comportamento das direções de drenagem em relação à ordem do rio indicam o elevado grau de assimetria entre as vertentes oceânica e continental. Os vales de terceira ordem, onde ocorrem os solos derivados de sedimentos são muito bem marcados na direção NW na vertente oceânica, enquanto que na vertente continental ocorre uma maior dispersão entre as direções NE e NW. Esta maior dispersão na vertente continental deve-se às características do substrato, um saprolito com formas de relevo multiconvexas e dissecação mais aleatória.

\subsection{Aspectos Pedológicos}

Foram determinadas sete unidades de mapeamento representativas na escala de mapeamento, 1:100.000 (Embrapa, 2006): Afloramentos Rochosos (RA1); Neossolo Litólico distro-úmbrico (RLdh1, RLdh2); Cambissolo Háplico distrófico (CXbd1, CXbd2, Cxbd3) e Latossolo Amarelo distrófico (LAd1).

As classes de solos observadas nas toposseqüências apresentam polaridade evolutiva do topo para a base das vertentes (Figura 9): afloramentos rochosos, Neossolo Litólico, Cambissolo Háplico, Argissolo Amarelo (classe em associação nas unidades de mapeamento), Latossolo Amarelo. A idéia de polaridade evolutiva relaciona a posição do solo no relevo e o seu grau de evolução. No caso estudado, os solos aumentam progressivamente a maturidade do topo para a base das vertentes.

A seguir são apresentados os contextos das unidades de mapeamento de solos.

\section{Afloramentos Rochosos (RA1)}

Essa unidade foi observada com maior expressão na ruptura brusca de relevo nos limites dos planaltos, entre a 

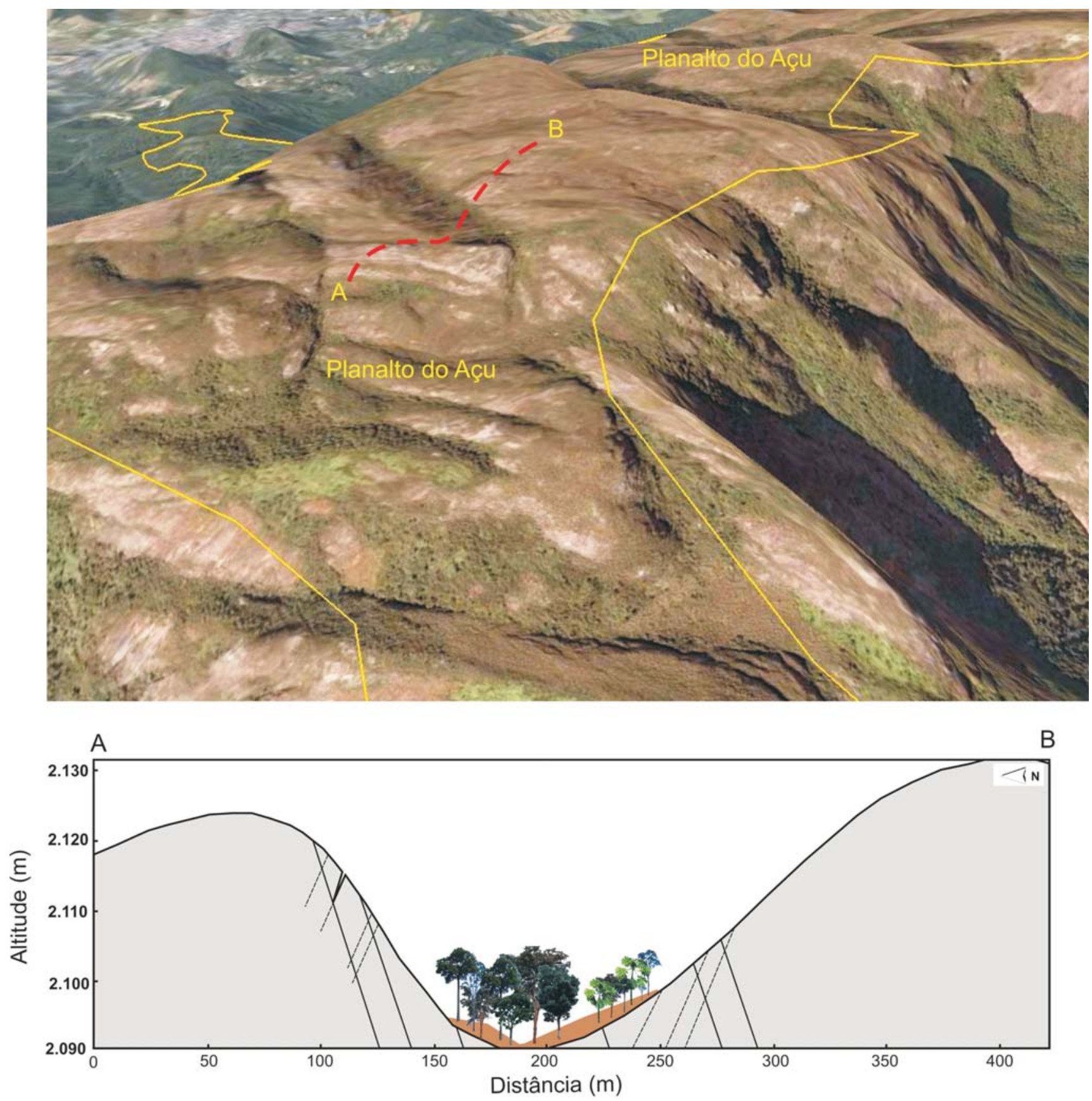

Sistema de Fraturas

Figura 5 - Assimetria das vertentes no Planalto do Açu em perspectiva. Fonte: Google Earth

vertente continental e a vertente oceânica, associada à escarpa de falha NE-SW. A ocorrência contínua de afloramentos rochosos nesta porção deve-se às maiores declividades e amplitudes altimétricas. As tramas isotrópicas dos minerais e a estrutura maciça dos granitos diminuem a taxa de intemperismo relativa e permite a preservação da rocha fresca exposta na superfície, típicas de relevos graníticos em margens continentais passivas (Ollier, 1985). O intemperismo diferencial ocorre especialmente por esfoliação esferoidal a partir de fraturas, caracterizando as formas arredondadas de 


\section{A}

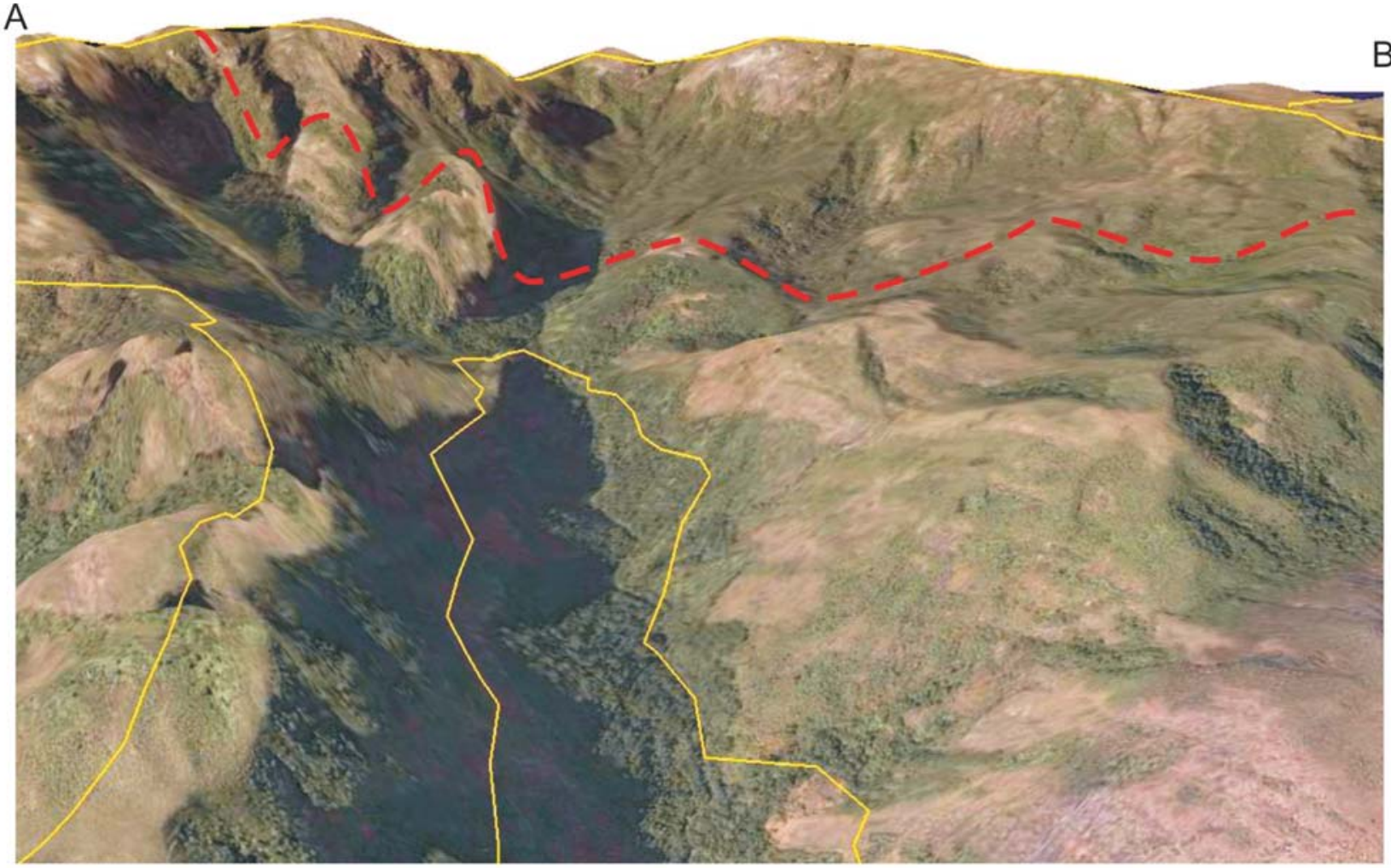

A

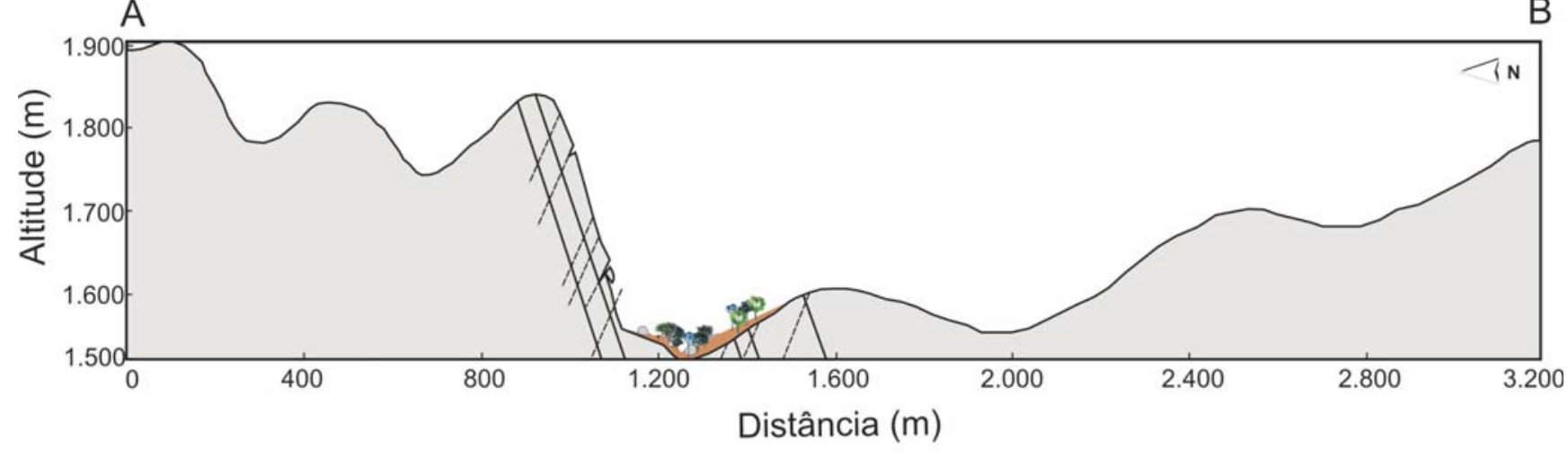

B

$B$

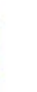



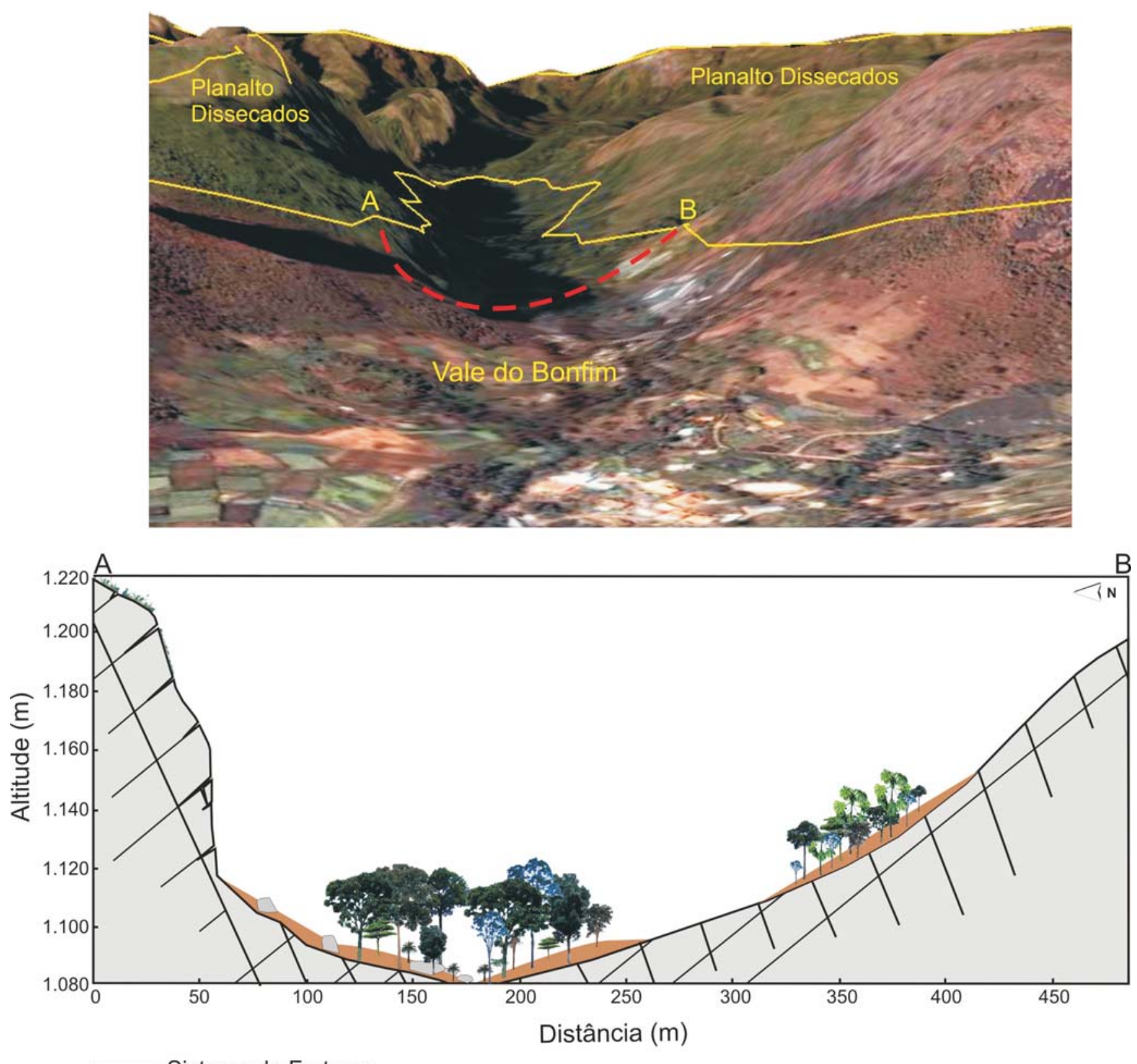

\section{Sistema de Fraturas}

Figura 7 - Assimetria das vertentes do Vale do Bonfim em perspectiva. Fonte: Google Earth

verifica menor cobertura dos campos. Deste modo, foi determinada uma unidade de mapeamento de Neossolos Litólicos associados aos afloramentos rochosos (RLdh1).

Os Neossolos Litólicos ao sul do Planalto do Açu, na vertente continental, e em algumas porções dos planaltos dissecados apresentam maior expressividade dos Campos de Altitude e uma associação com Gleissolos, especialmente Gleissolos Melânico alítico (Rldh2). Estes ambientes indicam uma elevada acumulação de matéria orgânica, diretamente formada sobre o substrato rochoso impermeável e de baixa declividade dos Planaltos. Ao longo de fraturas e de abaciamentos naturais podem ocorrem acumulações locais que explicariam a formação dos Campos de Altitude mais extensivos. A maior acumulação de matéria orgânica comparada a outros ambientes se deve também a menor temperatura em altitudes mais elevadas, acima de $2.000 \mathrm{~m}$.

\section{Cambissolo Háplico distrófico (CXbd1, CXbd2, CXbd3)}

A unidade de mapeamento mais expressiva de Cambissolo Háplico distrófico (Cxbd1) está relacionada à 


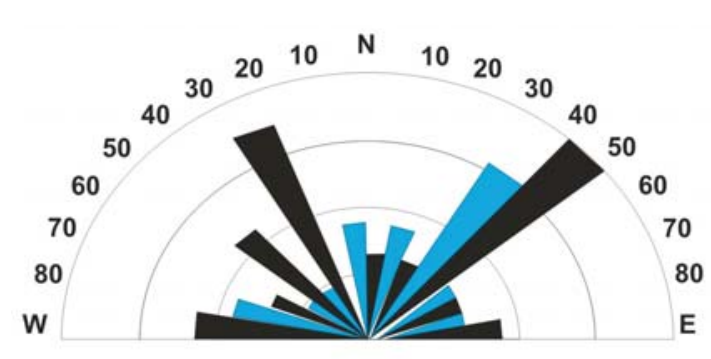

Rios de $1^{\circ}$ Ordem nas Escarpas Serranas

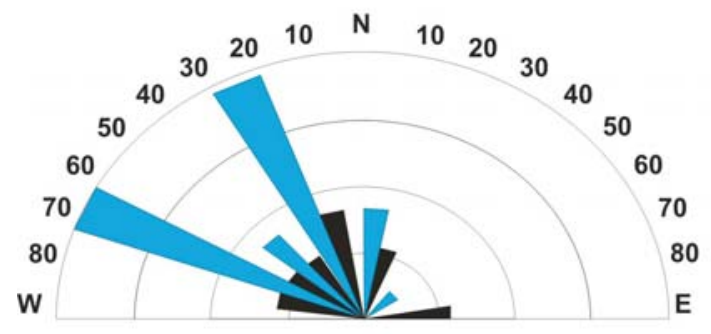

Rios de $2^{\circ}$ Ordem nas Escarpas Serranas

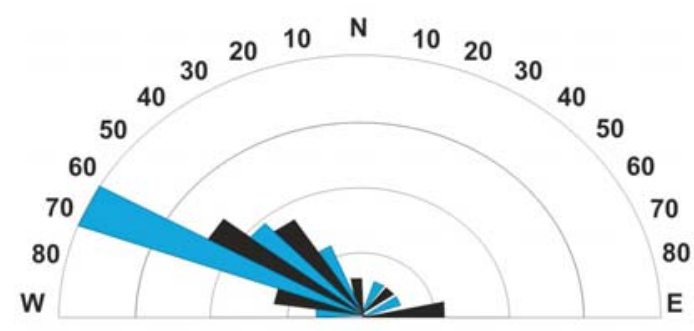

Rios de $3^{\circ}$ Ordem nas Escarpas Serranas

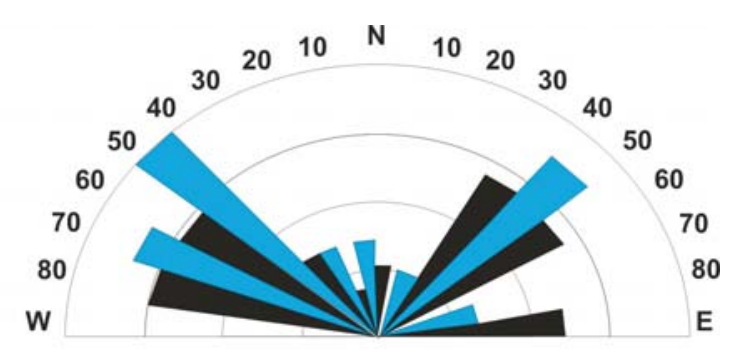

Rios de $1^{\circ}$ Ordem nos Planaltos Serranos

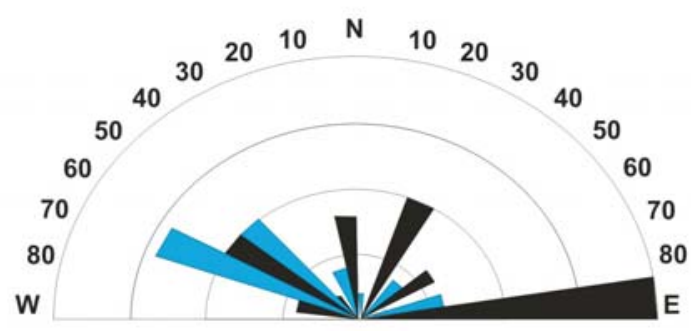

Rios de $2^{\circ}$ Ordem nos Planaltos Serranos

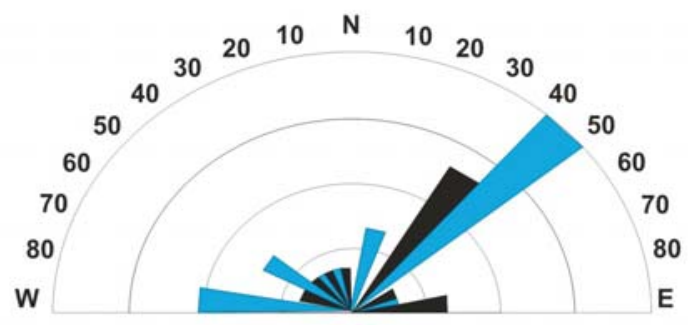

Rios de $3^{\circ}$ Ordem nos Planaltos Serranos

Figura 8 - Freqüência Absoluta da drenagem na vertente oceânica (Escarpas Serranas) e vertente continental (Planaltos Serranos).

vertente continental e rochas de estrutura gnáissica, em relevo suave ondulado a ondulado nos planaltos dissecados multiconvexos. A classe componente desta unidade mais representativa é Cambissolo Háplico Ta distrófico. Localmente, observou-se em campo a ocorrência de Argissolo Vermelho-Amarelo distrófico (5\% da unidade) em drenagens encaixadas e com largura inferior a $10 \mathrm{~m}$.

Os substratos destes solos são formados por saprolitos de rochas com estrutura gnáissica ou de fluxo ígneo. O intemperismo mais intenso está relacionado à anisotropia formada pela foliação penetrativa, que permite a percolação mais intensa de água entre os grãos, em comparação aos granitos. Outra explicação importante é a sua localização no alto estrutural dos Planaltos Dissecados. Em ambientes similares como nos altos estruturais da Serra da Mantiqueira são formados níveis bauxíticos no interior da trama do saprolito devido à elevada taxa de percolação de água, como observado na Serra dos Órgãos, mas também devido à composição mineralógica com predomínio de feldspatos (Furian et al., 1999, 2002). Na Serra dos Órgãos não foram observados estes níveis bauxíticos, possivelmente devido à composição granítica mais enriquecida em micas e quartzo.

A associação Cambissolo Háplico distrófico com Neossolo Litólico distro-úmbrico (Cxbd2) foi caracterizada na vertente oceânica, nas porções abaixo da escarpa de falha (unidade RA1), onde a declividade é menor e o relevo é ondulado a suave-ondulado, associado à Floresta Pluvial Alto-Montana (Rizzini, 1979), numa proporção de 70\% de Cambissolo e 30\% de Neossolo Litólico. 


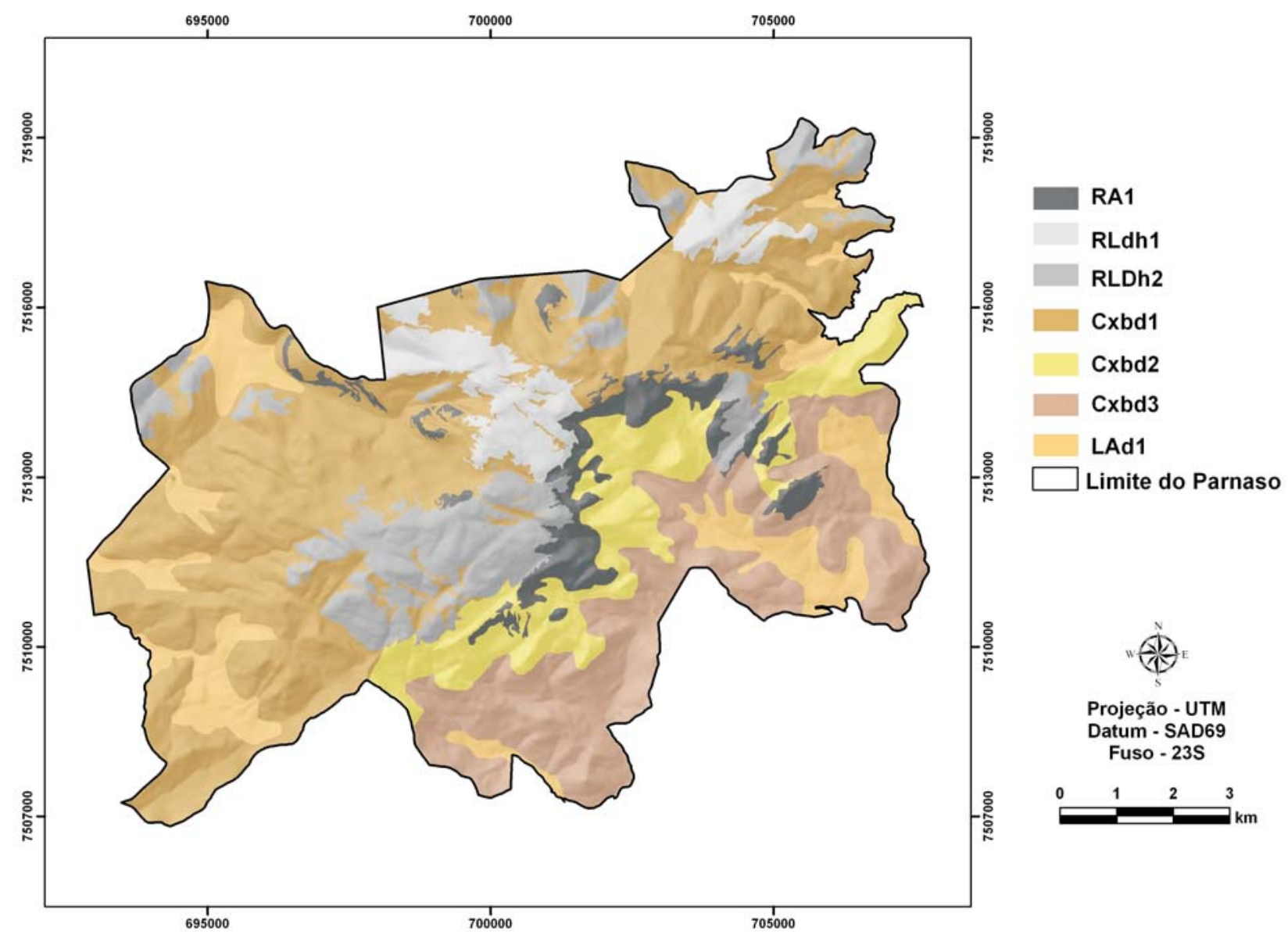

Figura 9 - Mapa esquemático de Solos do Parque Nacional da Serra dos Órgãos.

Na vertente oceânica ocorre uma associação de Cambissolo Háplico distrófico com Latossolo Amarelo distrófico (CXbd3), na transição entre a unidade anterior (Cxbd2) e os vales de fundo chato. Esta unidade é caracterizada por uma maior área de deposição e aumento da umidade que compõe uma paisagem de Floresta Pluvial Montana (Rizzini, 1979), numa proporção de $80 \%$ de Cambissolo e 20\% de Latossolo.

\section{Latossolo Amarelo distrófico (LAd1)}

O Latossolo Amarelo distrófico ocorre em vales encaixados formados por áreas de deposição com baixa declividade derivados de depósitos de escorregamentos antigos em vales de terceira ordem ou maiores, de direção NW-SE, tanto da vertente continental, como da vertente oceânica. Este solo apresenta textura média, relação silte/argila $<5$, e matiz 7,5 YR. Nos planaltos dissecados da vertente continental, em vales de segunda e terceira ordem, sua ocorrência foi identificada em associação com Argissolo
Bruno-Acinzentado alítico e Argissolo Amarelo distrófico. O primeiro se caracteriza por apresentarem a parte superior do horizonte B (inclusive BA) pouco mais escurecida em relação aos sub-horizontes inferiores, com matiz 5 YR ou mais amarelo, valor 3 a 4 e croma menor ou igual a 4 (Embrapa, 2006). Além disso, foi observada grande quantidade de matéria orgânica e saturação de alumínio e” 50 \% no horizonte A. Já o Argissolo Amarelo distrófico apresenta matiz 7,5YR ou mais amarelos nos primeiros centímetros do horizonte B e saturação por base $<50 \%$.

Ocorrem ainda Chernossolos associados localmente aos Argissolos nos vales, possivelmente controlados por variações do material de origem, com maior contribuição de sedimentos de rochas básicas.

\subsection{Superfície de Aplainamento Japi}

Nos divisores do topo dos Planaltos ocorrem localmente campos sobre Plintossolos Pétricos concrecionários. Lateralmente e mais abaixo nas vertentes, nos contatos entre os Planaltos e os Planaltos Dissecados, 
ocorre Plintossolo Háplico com horizonte plíntico (acumulações não-endurecidas de óxidos e hidróxidos de ferro) sobre matriz de saprolito. Nos Planaltos Dissecados ocorre espessos saprolitos, como foi descrito anteriormente. Este conjunto indica um regolito laterítico em processo de denudação e estaria associado à formação da superfície de aplainamento Japi (Almeida, 1964) ou Sul-Americana (King, 1956).

O horizonte concrecionário nos Planaltos ocorre subaflorante e apresenta espessura de poucas dezenas de centímetros. As concreções centimétricas são soltas e apresentam evidências de desmantelamento no meio de uma matriz mais fina. Logo abaixo deste horizonte pode-se observar a presença de saprolito com manchas e mosqueados ferruginosos.

Os estudos de Neotectônica indicam que a superfície Japi foi deformada tectonicamente por sobrelevação nos altos estruturais da Serra do Mar e Serra da Mantiqueira (Almeida, 1964; Modenesi-Gautieri et al., 2002; Ferrari, 2001; Hartwig, 2006; Riccomini, 1989). Os dados obtidos aqui indicam a presença da superfície de aplainamento, mas não necessariamente de uma sobrelevação, pois a presença de horizonte plíntico mostra que as concreções ferruginosas podem ser formadas nestas condições ambientais. Uma alternativa seria a presença de uma superfície de aplainamento naturalmente irregular em sua origem com vários escalonamentos derivados do controle litoestrutural. Os altos estruturais da Serra do Mar e da Serra da Mantiqueira seriam residuais e formados pelo basculamento de blocos e desenvolvimento de grábens. As altitudes irregulares dos planaltos poderiam ser provenientes de um processo de etchplanação anterior à neotectônica. Entretanto, este é um debate que deve ser desenvolvido com mais evidências (Vitte, 2005).

\subsection{Classificação das Catenas}

Apesar do estudo em escala 1:100.000, pode-se observar uma organização pedológica evolutiva com polaridade do topo para a base das vertentes. Os solos menos evoluídos ocorrem no topo, relacionados com ambientes erosionais (afloramento rochoso, Neossolo Litólico, Cambissolo Háplico), e os mais evoluídos na base, associados a ambientes deposicionais (Argissolo Amarelo, Latossolo Amarelo).

Na acepção de Sommer e Schlichting (1997), o equilíbrio destas vertentes erosionais e deposicionais poderia levar a classificar como catenas de translocação. Essas catenas de translocação (translocation catenas), como já mencionado, são subtipos das de lixiviação ou de acumulação, onde as transferências e acumulações estão em equilíbrio. Dentro desse contexto, podem-se observar solos de maior maturidade nos vales alongados com depósitos sedimentares estáveis. Além disso, as facetas trapezoidais descritas por Hartwig (2006) indicam que esta sedimentação fica confinada e estável por muito tempo. Este processo se repete em várias escalas e pode ser observado em todas as unidades geomorfológicas.

\section{Conclusões}

Os solos das vertentes continentais e oceânicas mostram diferentes seqüências de evolução. Na vertente continental, os solos apresentam polaridade evolutiva crescente entre o topo e a base das vertentes, com a seguinte toposseqüência: afloramentos rochosos, Neossolos Litólicos, Cambissolos, Argissolos e Latossolos. Por outro lado, a vertente oceânica mostra uma toposseqüência truncada, também com polaridade evolutiva do topo para a base: afloramentos rochosos, Cambissolos e Latossolos. A assimetria das vertentes é marcada pela escarpa oceânica formada por uma importante zona de falha na direção NE-SW. Os Neossolos Litólicos são associados localmente a Gleissolos, a afloramentos rochosos e Plintossolos Pétricos associados às porções planálticas, desenvolvidos sobre granitos equigranulares e isotrópicos. Os Cambissolos são associados localmente a Plintossolos e Neossolos Litólicos e ocorrem sobre relevos multiconvexos relacionados com saprolitos de rochas gnáissicas ou de estrutura de fluxo ígneo. Os Latossolos são associados localmente a Argissolos e Chernossolos em depósitos formados em porções deprimidas de vales encaixados e formados por facetas trapezoidais. Estes ambientes refletem o contínuo processo de erosão e de movimentos de massa das porções mais elevadas e a formação de depósitos e intemperização nas porções mais baixas.

\section{Referências Bibliográficas}

Almeida, F.F.M. (1964) Fundamentos geológicos do relevo paulista. Boletim do Instituto Geográfico e Geológico, São Paulo, 41: 167-263.

Alonso, M.T.A. (1977) Vegetação. In: Goldenberg, C. (ed.). Geografia do Brasil: Região Sudeste. Rio de Janeiro: IBGE. 3: 91-118.

Asmus, H.E. \& Ferrari, A.L. (1978) Hipótese sobre a causa do tectonismo cenozóico na região Sudeste do Brasil. In: Aspectos Estruturais da Margem Continental Leste e Sudeste do Brasil. Rio de Janeiro: PETROBRÁS, Série REMAC, vol. 4, p. 75-88.

Assumpção, M. (1992) The regional intraplate stress field in South America. Journal of Geophysical Research, 97 (B8): 11889-11903.

Bocquier, G. (1971) Genèse et évolution de deux toposéquences de sols tropicaux Du Tchad - 
Interprétations biogeodynamique. Tese de Doutorado, Universidade de Strasbourg, Mémoire ORSTOM (Off. Rech. Sci. Tech. Outre-mer), Paris, v. $62 ., 350 \mathrm{p}$.

Bockheim, J.G.; Gennadiyev, A.N., Hammer, R.D. \& Tandarich, J.P. (2005) Historical development of key concepts in pedology. Geoderma, 124: 23-36.

Boulet, R. (1978) Toposéquences de sols tropicaux em HauteVolta: équilibres et deséquilibres pédobioclimatiques. Tese de Doutorado, Universidade de Strasbourg, Mémoire ORSTOM (Off. Rech. Sci. Tech. Outre-mer), Paris, v. 85, 272p.

Brasil. Ministério das Minas e Energia. Projeto Radambrasil. (1983) Ministério das Minas e Energia. Secretaria Geral - Folhas SF. 23/24 Rio de Janeiro/Vitória. Geologia, v. 32, p. 56-66.

Chauvel, A. (1976) Recherches sur la transformation des sols ferrallitiques dans la zone tropicale á saisons contrastées. Tese de Doutorado, Universidade de Strasbourg, Mémoire ORSTOM (Off. Rech. Sci. Tech. Outre-mer), Paris, v. 62., 532 p.

Cordani, V.G. \& Girardi, V.A.V. (1967) Geologia da folha de Morretes. Boletim Paranaense de Geociências, 26: $1-40$.

Daniels, R.B.; Gamble, E.E. \& Cady, J.G. (1971) The relation between geomorphology and soil morphology and genesis. Advances in Agronomy, 23: 51-88.

Dantas, M.; Shinzato, E., Medina, A.I.M., Pimentel, J.; Silva, C.R.; Lumbreras, J.F.; Calderano, S.B. \& Carvalho Júnior, A. (2001) Diagnóstico Geoambiental do Estado do Rio de Janeiro. Brasília: CPRM. 35 p.

Davis, E.G. \& Naghettini, M.C. (2000) Estudos de chuvas intensas no Estado do Rio de Janeiro. 2 ed. Revista Ampliada. Brasília: CPRM/Serviço Geológico do Brasil. 140 p.

Delvigne, J. (1965) Pédogenèse en zone tropicale: la formation des minéraux secondaires en milieu ferralitique. Mémoire ORSTOM (Off. Rech. Sci. Tech. Outre-mer), Paris, vol. 13, 117 p.

de Ploey, Y. \& Cruz, O. (1979) Landslides in the Serra do Mar, Brazil. Catena, 6 (2): 111-122.

EMBRAPA - Empresa Brasileira de Pesquisa Agropecuária. (1992) Mapa de Solos do estado do Rio de Janeiro. Rio de Janeiro: EMBRAPA-SNLCS. Disponível em: $<$ www.cnps.embrapa.br $>$. Acesso em 24 de outubro de 2006.
EMBRAPA - Empresa Brasileira de Pesquisa Agropecuária. (2006) Sistema Brasileiro de Classificação de Solos. Rio de Janeiro: EMBRAPA-SPI. 412 p.

EMBRAPA - Empresa Brasileira de Pesquisa Agropecuária. (1997) Manual de métodos de análise de solo. 2. ed. Rio de Janeiro: EMBRAPA - CNPS. 212 p.

Erhardt, H. (1956) La genèse des sols en tant que phénomène géologique. Esquisse d'une théorie géologique et géochimique: biostasie et rhexistasie. Paris: Masson et Cie., Evolution des Sciences, n. 8, 90 p.

Ferrari, A.L.; Melo, E.F.; Vaz, M.A.; Dalcomo; M.T.; Brenner, T.L.; Silva, V.P. \& Nassar, W.N. (1981) Folha Itaboraí, Maricá, Saquarema, e Baía de Guanabara. Projeto Carta Geológica do Estado do Rio de Janeiro. Rio de Janeiro: DRM/Geomitec.

Ferrari, A.L. (2001) Evolução Tectônica do Gráben da Guanabara. 412 f. Tese (Doutorado em Geologia) - Instituto de Geociências, USP, São Paulo.

Furian, S.; Barbiero, L. \& Boulet, R. (1999) Organisation of the soil mantle in tropical southeastern Brazil (Serra do Mar) in relation to landslides processes. Catena, 38: 65-83.

Furian, S.; Barbiero, L.; Boulet, R.; Curmi, P.; Grimaldi, M. \& Grimaldi, C. (2002) Distribution and dynamics of gibbsite and kaolinite in an Oxisol of Serra do Mar, southeasthern Brazil. Geoderma, 106: 83-100.

Gobin, A.; Campling, P. \& Feyen, J. (2001) Soil-landscape modeling to quantify spatial variability of soil texture. Phys. Chem. Earth (B), 26: 41-45.

Graham, R.C.; Diallo, M.M. \& Lund, L.J. (1990) Soils and mineral weathering on phyllite colluvium and serpentinite in northwestern California. Soil Science Society of America Journal, 54: 16821690.

Hartwig, M.E. (2006) Tectônica rúptil Mesozóico-Cenozóica na região da Serra dos Órgãos, RJ. 117 f. Dissertação (Mestrado em Geologia) - Instituto de Geociências, USP, São Paulo.

Hutchinson, M.F. (1989) A new procedure for gridding elevation and stream line data with automatic removal of spurious pits. Journal of Hydrology, 106: 211-232.

ICMBio - Instituto Chico Mendes de Conservação da Biodiversidade. (2007). Plano de Manejo do Parque Nacional da Serra dos Órgãos. Brasília: Instituto Chico Mendes de Conservação da Biodiversidade. 365p. 
INMET - Instituto Nacional de Meteorologia. (2007) Climatologia. Disponível em $<$ www.inmet.gov.br>. Acesso 30 de março de 2007.

Jenson, S.K. \& Domingue, J.O. (1987) Extracting topographic structure from digital elevation data for geographical information system analysis. Photogrammetric Engineering \& Remote Sensing, 54: 1593-1600.

Juma, N.G. (1999) The pedosphere and its dynamics. A systems approach to soil science. Volume 1: introduction to soils science and soil science resources. Edmonton: Salman Productions, University of Alberta. 315p.

King, L.C. (1956) A geomorfologia do Brasil Oriental. Revista Brasileira de Geografia, 18: 147-265.

Lagacherie, P.; McBratney, A.B. \& Voltz, M. (2006) Digital soil mapping: An introductory perspective. Elsevier. $600 \mathrm{p}$.

Martinelli, G. (1989) Campos de altitude. Rio de Janeiro: Editora Index, $158 \mathrm{pp}$.

Martz, L.W. \& Garbrecht, J. (1995) Automated recognition of valley lines and drainage networks from grid digital elevation models: a review and a new method comment. Journal of Hydrology, 167: 393-396.

Martins, E.S.; Reatto, A.; Carvalho Júnior, O.A. \& Guimarães, R.F. (2004) Ecologia de paisagem: conceitos e aplicações potenciais no Brasil. Boletim de Pesquisa da Embrapa Cerrados, 121: 1-35.

Milne, G. (1934) Some suggested units of classification and mapping particularly for east African soils. Soil Research, 4: 183-198.

Myers, N.; Mittermeier, R.A.; Mittermeier, C.G.; Fonseca, G.A.B. \& Kent, J. (2000) Biodiversity hotspots for conservation priorities. Nature, 403: 853-858.

Modenesi-Gautieri, M.C.; Hiruma, S.T. \& Riccomini, C. (2002) Morphotectonics of a high plateau on nortwestern flank of the Continental Rift of southeastern Brazil. Geomorphology, 43: 257-271.

Nimer, E. (1977) Clima. In: Goldenberg, C. (ed.). Geografia do Brasil: Região Sudeste. Rio de Janeiro: IBGE, 3: 51-89.

O’Callaghan J. F. \& Mark, D. M. (1984) The extraction of drainage networks from digital elevation data. Computer Vision, Graphics, and Image Processing, 28: 323-344.

Oliveira, S.N.; Carvalho Junior, O.A.; Martins, E.S.; Silva, T.M.; Gomes, R.A.T.; Guimarães, R.F. (2007)
Identificação de Unidade de Paisagem e sua implicação para o ecoturismo no Parque Nacional da Serra dos Órgãos, Rio de Janeiro. Revista Brasileira de Geomorfologia. (neste volume).

Ollier, C.D. (1985) Morphotectonics of passive continental margins: introduction. Z. Geomorphol. N.F. Suppl., 54: $1-9$.

Penha, H.; Ferrari, A.L.; Ribeiro, A.; Amador, E.S.; Pentagna, F.V; Junho, M.C.B. \& Brenner, T.L. (1979) Folha Petrópolis. Projeto Carta Geológica do Estado do Rio de Janeiro. Rio de Janeiro: DRM/UFRJ.

Pinto, C.P.; Serpa, J.C.; Dutra, J.E.B.; Hettich, M. \& Andrade, N.T. (1980) Folhas Anta, Duas Barras, Teresópolis e Nova Friburgo. Projeto carta geológica do estado do Rio de Janeiro. Rio de Janeiro: DRM/ Geosol.

Queiroz-Neto, J.P. (2002) Análise estrutural da cobertura pedológica no Brasil: uma experiência de ensino e pesquisa. Revista do Departamento de Geografia -USP, 15: 77-90.

Riccomini, C. (1989) O Rift continental do sudeste do Brasil. $256 \mathrm{f}$. Tese (Doutorado em Geologia), Instituto de Geociências, Universidade de São Paulo, São Paulo.

Rizzini, C.T. (1979) Tratado de fitogeografia do Brasil. São Paulo: Hucitec, 2 ed. 374 p.

Rossi, M. \& Pfeifer, R.M. (1991) Pedologia do Parque do Estadual da Serra do Mar. I: Levantamento de reconhecimento de solos. Revista do Instituto Florestal, 3 (1): 45-65.

Rossi, M. \& Queiroz-Neto, J.P. (2001) Relações Solo/ Paisagem em Regiões Tropicais Úmidas: o exemplo da Serra do Mar em São Paulo, Brasil. Revista do Departamento de Geografia - USP, 14: 11-23.

Silva, L.C.; Santos, R.A.; Delgado, I.M. \& Cunha, H.C.S. (2000) Mapa geológico do Rio de Janeiro, escala 1:50.000. Rio de Janeiro: Serviço Geológico do Brasil (CPRM) - Divisão de Geologia Básica, Departamento de Recursos Minerais (DRM).

Silva, T.M. (2003) A estruturação geomorfológica do Planalto Atlântico no Estado do Rio de Janeiro. In: Simpósio Brasileiro de Geografia Física Aplicada, 10., Rio de Janeiro. Anais do X SBGFA, Rio de Janeiro: UERJ. 11 p.

Sommer, M. \& Schlichting, E. (1997). Archetypes of catenas in respect to matter - a concept for structuring and grouping catenas. Geoderma, 76: 1-33. 
Strahler, A.N. (1952) Hypsometric (area-altitude) analysis and erosional topography. Bulletin of the Geological Society of America, 63 (10): 1117-1142.

Tarboton, D.G. (1997) A new method for the determination of flow directions and upslope areas in grid digital elevation models. Water Resources Research, 33 (2): 309-319.

Tarboton, D.G. (2005) Terrain Analysis Using Digital Elevation Models (TauDEM). Disponível em: $<$ http://hydrology.neng.usu.edu/taudem/> Acesso em 23 de abril de 2005.

Teramoto, E.R.; Lepsch, I.F. \& Vidal-Torrado, P. (2001) Relações solo, superfície geomórfica e substrato geológico na microbaciado ribeirão Marins (Piracicaba - SP). Scientia Agrícola, 58 (2): 361371.

Tupinambá, M. (1999) Evolução tectônica e magmática da Faixa Ribeira na região serrana do estado do Rio de Janeiro. 221 f. Tese (Doutorado em Geologia) - Instituto de Geociências, Universidade de São Paulo, São Paulo.
Turcotte, R.; Fortin, J.P.; Rousseau, A.N.; Massicotte, S. \& Villeneuve, J. P. (2001) Determination of the drainage structure of a watershed using a digital elevation. Journal of Hidrology, 240: 225-242.

Vidal-Torrado, P. \& Lepsch, I.F. (1999) Relações material de origem-solo e pedogênese em uma seqüência de solos predominantemente argilosos e latossólicos sobre psamitos na Depressão Periférica Paulista. Revista Brasileira de Ciência do Solo, 23: 357369.

Vitte, A.C. (2005) Etchplanação dinâmica e episódica nos trópicos quentes e úmidos. Revista do Departamento de Geografia - USP, 16: 105-118.

Zálan, P.V. (2004) Evolução Fanerozóica das Bacias Sedimentares Brasileiras, In: Mantesso-Netto, V.; Bartorelli, A.; Carneiro, C.D.R. \& Neves, B.B.B. (Eds.). Geologia do Continente Sul-Americano Evolução da Obra de Fernando Flávio Marques de Almeida. São Paulo: Beca Produções Culturais Ltda. p. 595-612. 